Original Research Article

\title{
Antihyperlipidemic activity of Chloroxylon swietenia in triton WR1339 induced hyperlipidemia
}

\author{
B. H. M. R. K. Guptha ${ }^{1}$, S. L. D. V. Ramana Murty Kadali2*, Vijay Kumar M. ${ }^{3}$, \\ Revanasiddappa B. C. ${ }^{3}$
}

${ }^{1}$ Department of Pharmacology, IQ City Medical College, Durgapur, West Bengal, India

${ }^{2}$ Department of Pharmacology, Modern Institute of Medical

Sciences, Indore, Madhya

Pradesh, India

${ }^{3}$ Department of Pharmaceutical Chemistry, NGSM Institute of Pharmaceutical Sciences of Nitte University, Mangalore, India

Received: 29 December 2017

Revised: 11 January 2018

Accepted: 29 January 2018

*Correspondence to:

Dr. S. L. D. V. Ramana Murty

Kadali,

Email: murtypharma@

gmail.com

Copyright: () the author(s), publisher and licensee Medip Academy. This is an openaccess article distributed under the terms of the Creative Commons Attribution NonCommercial License, which permits unrestricted noncommercial use, distribution, and reproduction in any medium, provided the original work is properly cited.

\begin{abstract}
Background: Medicinal herbs are beneficial and effective either in the management and prevention of several metabolic disorders, associated with hyperlipidemia, hypertension and insulin resistance which increases the cardiometabolic risk and demands for the life time therapy. Current allopathic medicines are expensive and reported with several adverse effects and hence, finding of a suitable herbal medicine for hyperlipidemic disorders is very important.

Methods: Thirty albino rats weighing 200-230g were randomly divided into 5 groups were rendered hyperlipidemia with a single dose of triton WR 1339. Normal control, positive control, standard, aqueous and ethanolic extract groups were treated with tween-80, tween-80, atorvastatin, aqueous and ethanolic extracts of Chloroxylon swietenia respectively for seven days. At the end of the study, blood was collected for estimation of the lipid profile.

Results: Both the aqueous and ethanolic extract groups significantly reduced the TG and VLDL levels.

Conclusions: The extracts exhibited remarkable activity on one or either parameter of the lipid profile. It could be due to the presence of alkaloids, steroids, flavonoids, coumarins and phenols in the extracts.
\end{abstract}

Keywords: Chloroxylon swietenia, Hyperlipidemia, Triton WR 1339

\section{INTRODUCTION}

Hyperlipidemia is a condition characterized by an increase in one or more of the plasma lipids, including triglycerides, cholesterol, cholesterol esters, phospholipids and or plasma lipoproteins including VLDL and LDL along with reduced HDL levels. ${ }^{1}$ 
Both the genetic inheritance and consumption of high carbohydrate or fat diets would lead to dyslipidemia and widely seen in developed countries. Hyperlipidemia is a cardinal sign of atherosclerosis and the other cardiovascular diseases, such as coronary heart disease, ischemic cerebrovascular disease and peripheral vascular disease. Cardiovascular disease is one of the leading causes of morbidity and mortality among the India and world-wide population. It contributes to nearly one-fourth of the deaths in the working age group of 25-65 years in the country. ${ }^{2}$ According to Indian Council of Medical Research (ICMR) survey conducted in different Indian states showed that the urban population has a higher prevalence of hypercholesterolemia than the rural population. $^{2}$

Elevated lipid levels result through either increased absorption from the gut or enhanced endogenous synthesis. Hyperlipidemia can be induced in animals by two ways.

- Diet manipulation- by feeding high-fat or carbohydrate diets for longer periods. Now a days, several types of high fat are available to induce hyperlipidemia. ${ }^{3-6}$

- $\quad$ Triton induced hyperlipidemia model. ${ }^{7,8}$

Hyperlipidemia can be controlled by two possible ways, viz., by blocking the endogenous synthesis or by decreasing fat absorption. Both these elements can be evaluated in normal animals with triton WR 1339 model and without dietary changes/manipulation. ${ }^{9}$

The current anti-hyperlipidemic therapy includes mainly statins and fibrates, correct the altered blood lipid profile by inhibiting the biosynthesis of cholesterol and the latter acts by enhancing the clearance of triglyceride rich lipoproteins. Several adverse effects were reported which includes hepatotoxicity, but the risk of myopathy, rhabdomyolysis and also not advisable during pregnancy. ${ }^{10}$ These adverse effects and drug interactions with statins are limiting its use in dyslipidemia and favors in search of medicinal plant products having hypolipidemic-phyto-active compounds. The investigation of plants will be a useful strategy in the breakthrough of novel lead molecules eliciting improved activity by regulating the different mechanisms maintaining the lipid metabolism and therefore can be utilized in treating hyperlipidemia of varied etiology.

Chloroxylon swietenia belongs to family Rutaceae. Common name - satinwood, Telugu name - billedu, bildu chettu, billu, Kannada: bittulla, huragalu, hurihuli, masula. Chloroxylon swietenia has been reported to have antiinflammatory activity, antimicrobial activity, analgesic activity, antioxidant activity, mosquitocidal activity antidiabetic activity. ${ }^{11-20}$ Antihyperlipidemic activity with this plant was not reported earlier. Based on this it was thought worthwhile to investigate the antihyperlipidemic activity of Chloroxylon switenia in triton induced hyperlipidemia in animal models.

\section{METHODS}

\section{Animals}

Wistar albino rats of either sex weighing 200-230 g were randomly divided into 5 groups $(n=6)$. The animals were allowed to acclimatize to the environment for seven days. The experimentation was approved by the IAEC (NGSMIPS/IAEC/December-2016/36).

\section{Chemicals}

Triton WR-1339 was obtained from Sigma Aldrich. All other chemicals used were of analytical grade and obtained from himedia and loba chemie; diagnostic kits from Aspen diagnostics Ltd.

\section{Experimental design}

Grouping and treatment schedule was shown in table-1. Triton $(400 \mathrm{mg} / \mathrm{kg})$ dissolved in normal saline and injected intraperitoneally to induce hyperlipidemia in rats. After 72 hours of triton injection, drug treatment was started and given continuously for seven days. The first group is healthy (normal control) and all the groups are hyperlipidemic rats. First and second group rats received tween-80 (p.o) for 7 days. $3^{\text {rd }}, 4^{\text {th }}, 5^{\text {th }}$ groups were treated with a single daily dose of atorvastatin $(40 \mathrm{mg} / \mathrm{kg})$, C.s aqueous extract (CAE) $(500 \mathrm{mg} / \mathrm{kg})$ and C.s ethanolic extract (CEE) $(500 \mathrm{mg} / \mathrm{kg})$ respectively for 7 days. On the $8^{\text {th }}$ day, the blood samples were collected from retro orbital sinus and centrifuged to separate the serum for biochemical estimation.

\section{Biochemical assays}

Serum total cholesterol (TC), triglycerides (TG) were estimated by the method of CHOD-PAP and high-density lipoprotein-cholesterol (HDL-c) by the method of GPOPAP. LDL, VLDL levels were determined by using Friedewald's formula. ${ }^{20}$

$\mathrm{VLDL}=\mathrm{TG} / 5$

$\mathrm{LDL}=\mathrm{TC}-\mathrm{HDL}-\mathrm{VLDL}$

Atherogenic index (AI) values were calculated by using formula as mentioned below: ${ }^{20}$

$\mathrm{AI}=(\mathrm{TC}-\mathrm{HDL}) / \mathrm{HDL}$

Coronary risk index (CRI) was calculated by using formula as mentioned below.

$\mathrm{CRI}=\mathrm{TC} / \mathrm{HDL}$ 
Table 1: Grouping and treatment schedule.

\begin{tabular}{|ll|}
\hline Group $(\mathbf{n = 6})$ & Drug and Dose \\
\hline I & Normal saline + Tween-80 \\
\hline II & Triton + Tween-80 \\
\hline III & Triton + Atrovastatin $40 \mathrm{mg} / \mathrm{kg}$ \\
\hline IV & Triton + CAE-500mg/kg \\
\hline V & Triton + CEE-500mg/kg \\
\hline $\begin{array}{l}\text { Post-treatment for } 7 \text { days after acute induction of } \\
\text { hyperlipidemia }\end{array}$ \\
\hline
\end{tabular}

\section{Statistical analysis}

All the results were expressed as Mean \pm SEM and subjected to One-way analysis of variance followed by Tukey's multiple comparison test using GraphPad prism 5.0 .

\section{RESULTS}

\section{Effect on TC}

TC levels were significantly elevated in positive control when compared with normal control. When compared with normal controls, standard group and ethanolic extract groups are significantly different $(\mathrm{F}=25.20, \mathrm{p}<0.01)$. Standard, ethanolic extract, and aqueous extracts groups are not significant when compared with positive control (Figure 1).

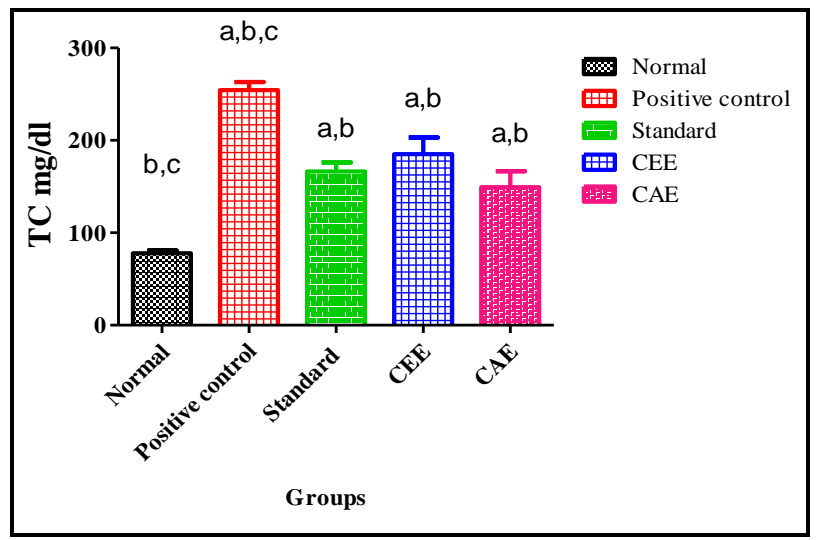

a Statistically significant from the normal control group. b Statistically significant from the positive control group. c Statistically significant from standard drug group.

Figure 1: The effect of CEE and CAE on TC in hyperlipidemic rats. Mean \pm SE $(n=6)$.

\section{Effect on TG}

TG levels were significantly elevated in positive control when compared with normal control. When compared with normal controls, standard group, ethanolic extract, and aqueous extracts groups are not statistically significant. Normal controls, standard group, ethanolic extract and aqueous extracts groups are statistically significant when compared with positive control $(\mathrm{F}=15.32, \mathrm{p}<0.001)$. This indicates that both aqueous and ethanolic extract treatment has reduced the triglyceride levels in the rats (Figure 2).

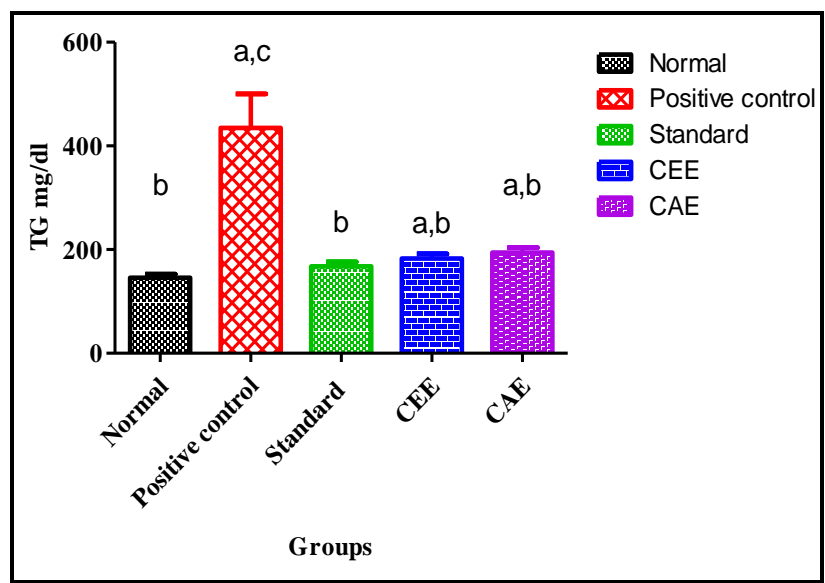

a Statistically significant from the normal control group. b Statistically significant from the positive control group. c Statistically significant from standard drug group.

Figure 2: The effect of CEE and CAE on TG in hyperlipidemic rats. Mean \pm SE $(n=6)$.

\section{Effect on HDL}

HDL levels were significantly reduced in hyperlipidemic rats (positive control) when compared with normal control. Normal controls, standard groups are statistically significant when compared with the positive control $(\mathrm{F}=$ 12.86, $\mathrm{p}<0.001)$. Ethanolic and aqueous extracts could elevate the HDL levels and but not statistically significant (Figure 3).

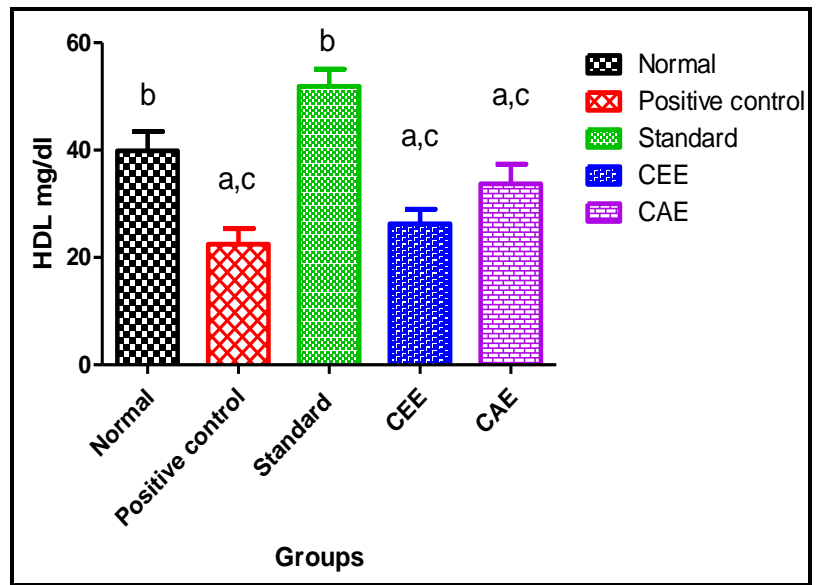

a Statistically significant from the normal control group. b Statistically significant from the positive control group. c Statistically significant from standard drug group.

Figure 3: The effect of CEE and CAE on HDL in hyperlipidemic rats. Mean $\pm \mathrm{SE}(\mathrm{n}=6)$.

\section{Effect on $L D L$}

LDL levels were significantly elevated in positive control when compared with normal control $(\mathrm{F}=15.94, \mathrm{p}<0.001)$. Standard group and aqueous extract group has decreased 
the LDL levels, but the decrease is not statistically significant (Figure 4).

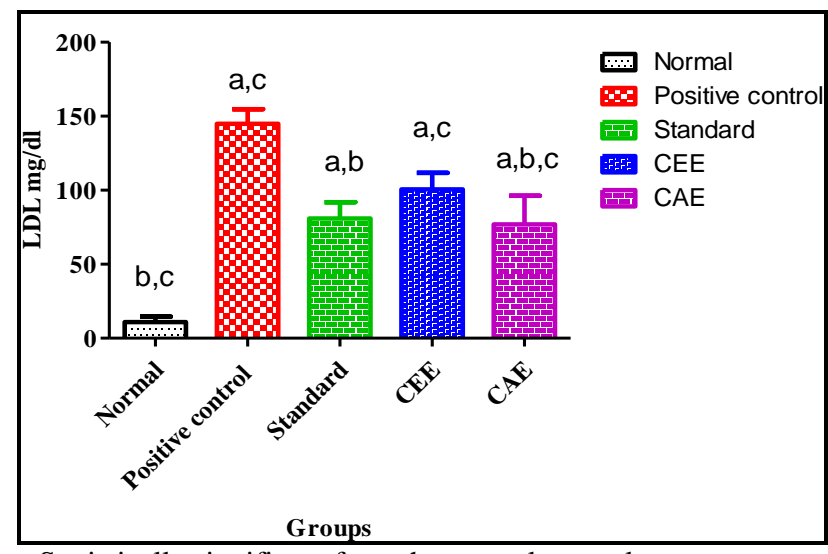

a Statistically significant from the normal control group.

b Statistically significant from the positive control group.

c Statistically significant from standard drug group.

Figure 4: The effect of CEE and CAE on LDL in hyperlipidemic rats. Mean \pm SE $(n=6)$.

\section{Effect on VLDL}

VLDL levels were significantly elevated in positive control when compared with normal control. When compared to the normal controls, standard group, ethanolic extract, and aqueous extracts groups not statistically significant. Normal controls, standard group, ethanolic extract and aqueous extracts groups are statistically significant when compared with positive control $(\mathrm{F}=$ 15.32, $\mathrm{p}<0.001)$. This indicates that both aqueous and ethanolic extract treatment has reduced the VLDL levels in the rats (Figure 5).

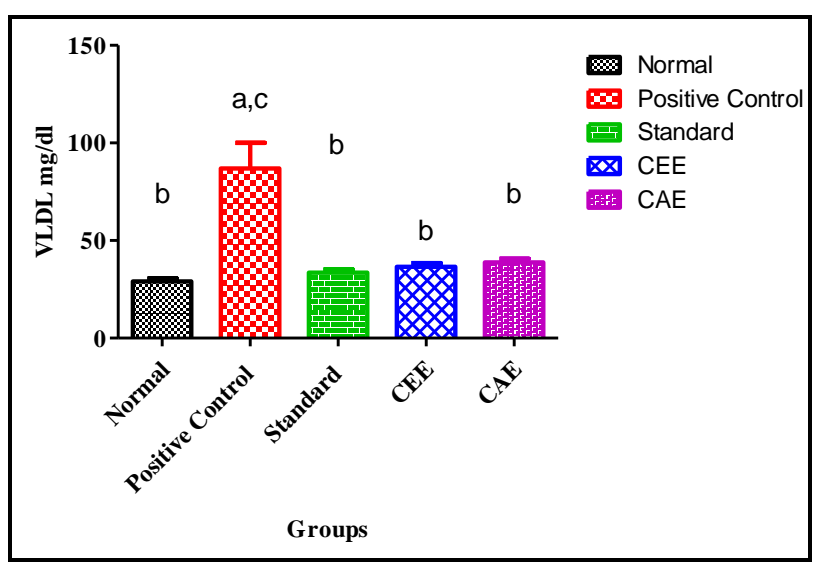

a Statistically significant from the normal control group.

b Statistically significant from the positive control group.

c Statistically significant from standard drug group.

Figure 5: The effect of CEE and CAE on VLDL in hyperlipidemic rats. Mean $\pm S E(n=6)$.

\section{Effect on AI and CRI}

Normal controls, standard group, ethanolic extract and aqueous extracts groups are statistically significant when compared with the positive control $(\mathrm{F}=14.61$, $\mathrm{p}<0.001)$. When compared to the normal controls, standard group, ethanolic extract, and aqueous extracts groups are not statistically significant. This indicates that both aqueous and ethanolic extract treatment has reduced the AI, CRI levels in the rats (Figure 6 and Figure 7).

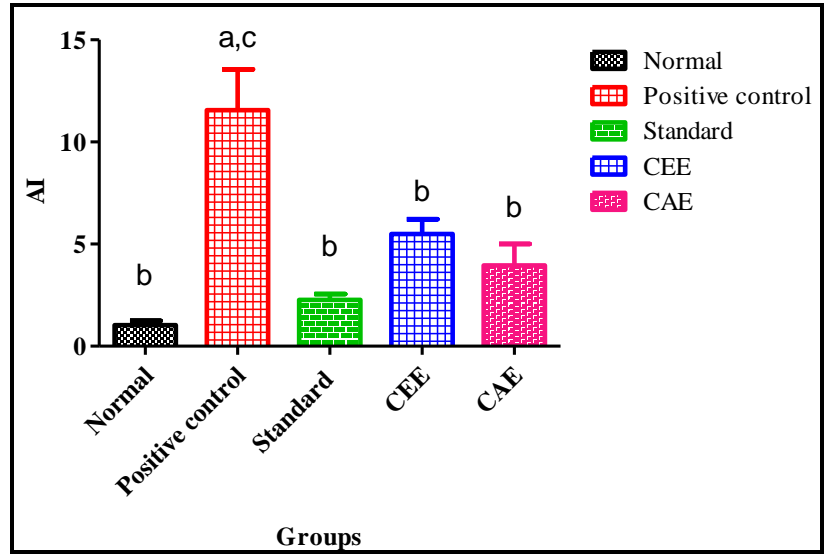

a Statistically significant from the normal control group. b Statistically significant from the positive control group. c Statistically significant from standard drug group.

Figure 6: The effect of CEE and CAE on AI in hyperlipidemic rats. Mean \pm SE $(n=6)$.

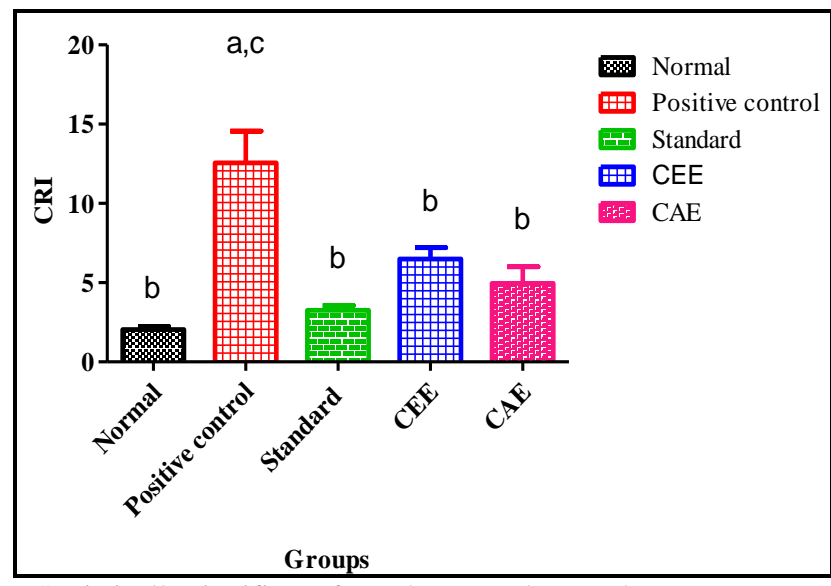

a Statistically significant from the normal control group.

b Statistically significant from the positive control group.

c Statistically significant from standard drug group.

Figure 7: The effect of CEE and CAE on CRI in hyperlipidemic rats. Mean \pm SE $(n=6)$.

\section{DISCUSSION}

Hyperlipoproteinaemias are mainly two type's i.e. Primary and Secondary. Primary hyperlipoproteinaemias are due to genetic or dietary and physical activity related. Secondary hyperlipoproteinaemias is associated with diabetes, myxoedema, nephrotic syndrome, chronic alcoholism, drugs (corticosteroids, oral contraceptives, $\beta$ blockers) etc. Primary hyperlipoproteinaemias is categorized in to type I (Familial lipoprotein lipase deficiency), type IIa (Familial hypercholesterolaemia), type IIb (Polygenic hypercholesterolaemia), type III (Familial 
dysbetalipoproteinaemia),

type

IV

(Hypertriglyceridaemia), type $\mathrm{V}$ (Familial combined hyperlipidaemia). ${ }^{10}$ The traditional system of medicine like Ayurveda, Unani and Chinese prescribe numerous herbal drugs for cardiovascular disorders. Recently herbal hypolipidemics have gained importance to fill the lacunae created by allopathic drugs. ${ }^{21}$

Triton WR-1339, a non-ionic detergent (oxyethylated tertiary octyl phenol formaldehyde polymer), widely accepted model to produce acute hyperlipidemia in animal models. ${ }^{22}$ Triton inhibits the lipoprotein lipase activity and thereby elevates the lipid profile. ${ }^{23}$ Triton WR-1339 inhibit the uptake of plasma triacylglycerol-rich lipoproteins by the peripheral tissues results in hyperlipidemia. ${ }^{24}$ It has been shown that triton WR 1339 increases the HMG-CoA reductase activity in the liver. ${ }^{25}$ The statins are the competitive inhibitors of HMG-CoA reductase, which are more effective and tolerable drugs for treating dyslipidemia. Atorvastatin is potent and long-acting statin in reducing LDL levels by increasing the synthesis of LDL receptors and reducing their degradation in hepatocytes at a higher dose. It can also reduce TG's levels to a certain extent by decreasing the hepatic production of VLDL and indirectly removing LDL precursors. ${ }^{26}$

Administration of triton to the rats leads to elevation of the total cholesterol, TG, and LDL with a significant reduction in HDL. The present study reveals the same results in comparison with various studies. Treatment with plant extracts has shown a significant decrease in TG, VLDL levels. Based on the results, it will be helpful in treating the type-IV hyperlipoproteinaemia (hypertriglyceridemia). This reduction may be due to either decrease in absorption of lipids from the gut or enhances the metabolism or utilization of lipid by activating the decrease the production of lipids by inhibiting the HMG CoA enzymes. Both the extracts significantly reduced the AI and CRI. It has been shown that atherogenic index is a strong marker to predict the risk of atherosclerosis and coronary heart disease. ${ }^{27} \mathrm{CRI}$ is an important predictor of cardiac disease mortality. ${ }^{28}$ The extracts exhibited remarkable antihyperlipidemic activity on one or either parameter of the lipid profile. It may be due to the presence of alkaloids, steroids, flavonoids, coumarins, and phenols in the extracts. Further studies are warranted to find out the active compound and the exact mode of action of the extracts in ameliorating the in triton induced acute hyperlipidemia in rats.

\section{ACKNOWLEDGEMENTS}

The authors are grateful to co-workers of the Department and Management for helping to carry out this project efficiently.

Funding: No funding sources

Conflict of interest: None declared
Ethical approval: The study was approved by the Institutional Animal Ethics Committee (NGSMIPS/IAEC/December-2016/36)

\section{REFERENCES}

1. Shattat GF. A Review Article on Hyperlipidemia: Types, Treatments and New Drug Targets. Biomed Pharmacol J. 2014;7(2):399-409.

2. Aslesh OP, Jayasree AK, Karunakaran U, Venugopalan AK, Divakaran B, Mayamol TR, et al. Prevalence of hypercholesterolemia among adults aged over 30 years in a rural area of north Kerala, India: a cross-sectional study. WHO South-East Asia J Public Health. 2016;5(1):70-5.

3. Rosini TC, Silva AS, Moraes CD. Diet-induced obesity: rodent model for the study of obesity-related disorders. Revista da Associacao Medica Brasileira. 2012 Jun;58(3):383-7.

4. Thirumalai T, Tamilselvan N, David E. Hypolipidemic activity of Piper betel in high fat diet induced hyperlipidemic rat. Journal of Acute Disease. 2014 Jan 1;3(2):131-5.

5. Matos SL, Paula HD, Pedrosa ML, Santos RC, Oliveira EL, Chianca Júnior DA, Silva ME. Dietary models for inducing hypercholesterolemia in rats. Brazilian Archives of Biology and Technology. 2005 Mar;48(2):203-9.

6. Raj CD, Jayanthi V, Manaswini VS, Gayathri R, Ranjani C, Brindha P. Effect of polyherbal formulation (OB-6) on high fat diet induced hyperlipidemia in rats. International Journal of Pharmacy and Pharmaceutical Sciences. 2012;4(2):31-5.

7. Girija K, Lakshman K. Anti-hyperlipidemic activity of methanol extracts of three plants of Amaranthus in triton-WR 1339 induced hyperlipidemic rats. Asian Pacific Journal of Tropical Biomedicine. 2011 Sep 1;1(1):S62-5.

8. Pasha SR. Evaluation of hypolipidemic activity of methanolic extract of ficus dalhousiaemiq. on triton-x and high fat diet induced hyperlipidemia in albino rats EJPMR. 2014;1(1):183-91.

9. Mishra R, Pandit K, Bhagwat AM, Brijesh S. Antihyperlipidemic activity of alcoholic extracts of trichosanthes anguina in triton WR 1339 induced hyperlipidemic rats. IJPSR. 2014;5(10):4269-74.

10. Tripathi KD. Hypolipidaemic drugs and plasma expanders. Essentials of Medical Pharmacology. 7th ed. New Delhi, Jaypee Brothers Medical Publishers (P) Ltd; Chapter 45; 2015:634-646.

11. Kumar K, Ganesh M, Baskar S, Srinivasan K, Kanagasabai R, Sambathkumar R, et al. Evaluation of Anti-inflammatory activity and toxicity studies of Chloroxylon swietenia in Rats. Anc Sci Life. 2006;3:33-43.

12. Prabakaran R, Arivoli S, Hema A, Kamatchi C. Isolation and characterization of flavonoids from Chloroxylon swietenia. J Chem Pharm Res. 2011;3(3):805-13. 
13. Ramadevi D. Antimicrobial activity on leaf extract of Chloroxylon swietenia. JGTPS. 2014;5(3):1940-42.

14. Harwansh RK, Pareta SK, Patra KC, Jangde R. Screening of Chloroxylon swietenia dc root for antibacterial and anthelmintic activities. Pharmacologyonline. 2011;1:544-52.

15. Pingale R, Dash GK. A Review on Ethnopharmacology, Phytochemistry and Bioactivity of Chloroxylon swietenia DC International Journal of Emerging Trends in Pharmaceutical Sciences. 2013;1(1):11-20.

16. Nayak JB. Comparative study of Chloroxylon swietenia leaf and bark against Culex quinque fasciatus mosquito larvae. International Journal of Multidisciplinary Research and Development. 2014;1(1):69-71.

17. Kiran SR, Bhavani K, Devi PS, Rao BR, Reddy KJ. Composition and larvicidal activity of leaves and stem essential oils of Chloroxylon swietenia DC against Aedes aegypti and Anopheles stephensi. Bioresource technology. 2006 Dec 1;97(18):2481-4.

18. Ravi Kiran S, Pillay VS, Reddy JK. Studies on mosquito larvicidal activity of Chloroxylon swietenia dc. Journal of pharmacognosy. 2012; 3(2):123-25.

19. Kadali RMSLDV, Das MC, Vijayaraghavan R, Shanmukha I. In vitro evaluation of antidiabetic activity of aqueous and ethanolic leaves extracts of Chloroxylon swietenia. Natl J Physiol Pharm Pharmacol. 2017;7(5):486-90.

20. Kadali RMSLDV, Das MC, Vijayaraghavan R, Vijay Kumar M. Evaluation of antidiabetic activity of aqueous and ethanolic leaf extracts of Chloroxylon swietenia in streptozotocin-induced diabetes in albino rats. Biomedical Pharmacology Journal. 2017;10(3):1347-53.

21. Pankti PD, Pragnesh VP. Anti hyperlipidemic activity of Tephrosia purpurea plant extracts in poloxomer 407 induced hyperlipidemic rats, Int Pharmacol Res. 2014;4(4):186-93.

22. Kumar G, Srivastava A, Sharma SK, Gupta YK. The hypolipidemic activity of Ayurvedic medicine, Arogyavardhini vati in Triton WR-1339-induced hyperlipidemic rats: a comparison with fenofibrate.
Journal of Ayurveda and integrative medicine. 2013 Jul;4(3):165

23. Ibrahim AY, Hendawy SF, Elsayed AA, Omer EA. Evaluation of hypolipidemic Marrubium vulgare effect in Triton WR-1339-induced hyperlipidemia in mice. Asian Pacific journal of tropical medicine. 2016 May 1;9(5):453-9.

24. Venkadeswaran K, Muralidharan AR, Annadurai T, Ruban VV, Sundararajan M, Anandhi R, et al. Antihypercholesterolemic and antioxidative potential of an extract of the plant, Piper betle, and its active constituent, eugenol, in triton WR-1339-Induced hypercholesterolemia in experimental rats. EvidenceBased Complementary and Alternative Medicine. 2014;2014. Available at: http://dx.doi.org/10.1155/2014/478973.

25. Pareek A, Chandurkar N, Tenpe CR, Yeole PG, Payghan R. Effect of Atorvastatin and Hydroxychloroquine Combination on Triton WR 1339 Induced Hyperlipidemia in Rats. Inventi Impact: Molecular Pharmacology. 2010;1(3).

26. Robert MW, Thomas BP. Drug Therapy for Hypercholesterolemia and Dyslipidemia. In: Laurence LB, Bruce AC eds. Goodman and Gilman's The Pharmacological Basis of Therapeutics. $11^{\text {th }}$ Ed. New York, McGraw-Hill; Chapter 31; 2006:948-953.

27. Shabnam N, Mohammad K, Majid KR, Maryam Abrishami, Mohammadreza J, Gholamhasan K, et al. Atherogenic Index of Plasma (AIP): A marker of cardiovascular disease. Med J Islam Repub Iran. 2015;29:240

28. Omotayo OE, Ndubuisi NN, Joseph LA, Ugochi AO, Chinonyelum TE, Basil C, et al. Nigerian Honey Ameliorates Hyperglycemia and Dyslipidemia in Alloxan-Induced Diabetic Rats. Nutrients. 2016;8(3):95.

Cite this article as: Guptha BHMRK, Kadali RMSLDV, Kumar VM, Revanasiddappa BC. Antihyperlipidemic activity of Chloroxylon swietenia in triton WR1339 induced hyperlipidemia. Int J Basic Clin Pharmacol 2018;7:518-23. 